\title{
Article \\ Multi-Functional Silver Nanoparticles for High-Throughput Endospore Sensing
}

\author{
Shinya Ikeno *(D), Takahiro Maekawa and Noriyasu Hara
}

check for

updates

Citation: Ikeno, S.; Maekawa, T.; Hara, N. Multi-Functional Silver Nanoparticles for High-Throughput Endospore Sensing. Biosensors 2022, 12, 68. https://doi.org/10.3390/ bios12020068

Received: 31 December 2021

Accepted: 24 January 2022

Published: 25 January 2022

Publisher's Note: MDPI stays neutral with regard to jurisdictional claims in published maps and institutional affiliations.

Copyright: (C) 2022 by the authors. Licensee MDPI, Basel, Switzerland. This article is an open access article distributed under the terms and conditions of the Creative Commons Attribution (CC BY) license (https:// creativecommons.org/licenses/by/ $4.0 /)$.
Department of Biological Functions Engineering, Graduate School of Life Science and Systems Engineering, Kyushu Institute of Technology, 2-4 Hibikino, Wakamatsu-ku, Kitakyushu 808-0196, Japan;

15965052mt@gmail.com (T.M.); noriyasuhara@gmail.com (N.H.)

* Correspondence: ikeno@life.kyutech.ac.jp

\begin{abstract}
In spore-forming bacteria such as Bacillus and Clostridium, the vegetative cells form highly durable hard shells called endospores inside the bacteria to survive as the growth environment deteriorates. Because of these properties, endospores can cause food poisoning and medical accidents if they contaminate food, medicine, or other products, and it is required for technology to detect the spores at the manufacturing site. In this study, we focused on the surface-enhanced Raman scattering (SERS) method for the sensitive detection of dipicolinic acid (DPA), a molecular marker of endospores. We constructed $\mathrm{Fe}_{3} \mathrm{O}_{4} / \mathrm{Ag}$ core-shell functional silver nanoparticles that specifically bind to DPA, and investigated a method for the qualitative detection of DPA by SERS and the quantitative detection of DPA by fluorescence method using a terbium complex formed on the surface. As a result, the concentration of the functional silver nanoparticles constructed could detect spore-derived DPA by fluorescence detection method, and SERS was several tens of $\mathrm{nM}$. The functionalized nanoparticles can detect DPA quantitatively and qualitatively, and are expected to be applied to detection technology in the production of food and pharmaceuticals.
\end{abstract}

Keywords: endospore; dipicolinic acid; surface-enhanced Raman scattering; functional silver nanoparticles; terbium complex

\section{Introduction}

Various disinfection/sterilization operations and microbiological tests are conducted in the food industry to prevent food poisoning and food spoilage/deformation due to bacterial contamination. As a general disinfection method, the use of alcohol (70-80\% ethyl alcohol) is often used in the food sanitation field. Sterilization methods include highpressure steam sterilization using an autoclave at $121^{\circ} \mathrm{C}$ for $15-20 \mathrm{~min}$ at 2 atmospheres, dry heat sterilization using a dry heat sterilizer at $160{ }^{\circ} \mathrm{C}$ or higher for at least $30 \mathrm{~min}$, boiling sterilization using boiling water, ultraviolet sterilization using ultraviolet radiation, and gas sterilization using ethylene oxide or propylene oxide [1,2]. In the pharmaceutical industry, raw materials are carefully cleaned and wiped from the time of delivery to minimize contamination by foreign substances and microorganisms. Sterilization methods include heat sterilization, moist heat sterilization, dry heat sterilization, irradiation sterilization, and sterilization by gas or fumigants, as described above. If heat sterilization is not possible for a liquid product, it is filtered and sterilized using a sterile filter of $0.22 \mu \mathrm{m}$ or less or a filter to catch microorganisms. The quality and hygiene of all processes from shipping delivery are monitored.

General nutritional vegetative bacteria can be sterilized using these methods because of their weak resistance. However, some bacteria that form durable structures called spores are resistant to heat, drying, ultraviolet rays, and chemicals, and cannot be easily sterilized by ordinary sterilization methods [3-5]. Bacteria that form such endospores include Bacillus and Clostridium species. These bacteria form spores from the vegetative cells to survive 
when the surrounding nutritional status or growth environment deteriorates. When the nutritional status of the surrounding environment recovers, the bacteria germinate from the endospores, become nutrient cells, and repeatedly divide and multiply. When these sporeforming bacteria are mixed into food or products, they remain in the food as endospores even after the food has been sterilized, and the bacteria germinate and multiply from there, causing food poisoning and food spoilage or loss [6-9]. Therefore, contamination with spore-forming bacteria has become a problem in food and pharmaceutical manufacturing sites. In the current detection methods, samples are cultured and the colonies are counted, so it takes several days to a week to obtain the results. In addition, endospore detection methods targeting dipicolinic acid (DPA), a molecular marker of endospores, have been developed, including an absorption method based on the chelation of DPA with metal ions [10-12], a fluorescence method based on the adsorption of DPA with lanthanides [13-16], and a highly sensitive fluorescence method based on the complexation of terbium complexes with DPA [17-20]. However, the absorption method has low sensitivity, while the fluorescence method has very high sensitivity but has the disadvantage of being strongly affected by foreign substances. Against this background, there is a strong need for a technology to detect endospores in situ, rather than as bacteria, as a rapid and reliable detection method.

In this study, we developed a novel detection method using functionalized silver nanoparticles for simple and sensitive spore detection. To detect spores qualitatively with high sensitivity, we focused on surface-enhanced Raman scattering (SERS) [21-24]. The SERS effect occurs on metal surfaces such as gold, silver, and copper, and the enhancement effect is especially remarkable when silver is used [25-27]. In this study, we constructed functional silver nanoparticles that specifically bind to DPA. A terbium complex is formed on the surface layer of the functionalized silver nanoparticles, and when DPA is coordinated to this complex, it shows very high fluorescence, which enables highly sensitive and quantitative detection. Additionally, since the SERS effect is remarkably obtained in the gaps between the aggregated nanoparticles [24], we used $\mathrm{Fe}_{3} \mathrm{O}_{4} / \mathrm{Ag}$ core-shell nanoparticles with a magnetic $\mathrm{Fe}_{3} \mathrm{O}_{4}$ core for easy aggregation. In addition, the magnetic nature of the nanoparticles allows them to be separated and collected by magnets, thus removing impurities. Therefore, the Raman signal enhanced by SERS allows qualitative analysis of the DPA signal. This study aims to establish a simple, sensitive, quantitative, and qualitative detection technique for spores by using these functional silver nanoparticles.

\section{Materials and Methods}

\subsection{Materials and Reagents}

2,6-Pyridinedicarboxylic acid, iron(II) sulfate heptahydrate, potassium nitrate, sodium hydroxide, silver nitrate, trisodium citrate dehydrate, hydroxylammonium chloride, oxalic acid, ammonium oxalate monohydrate, and terbium (III) chloride hexahydrate were obtained from Wako Pure Chemical Industries (Japan). Branched polyethylenimine, Mw $\sim 25,000$, was obtained from Sigma Aldrich. Standard suspension of Bacillus subtilis spore $\left(1.0 \times 10^{7} \mathrm{CFU} / \mathrm{mL}\right.$, Eiken Chemical Co., Ltd., Tokyo, Japan) was used as a target endospore for extraction of DPA.

\subsection{Extraction of DPA from Endospore}

Extraction of DPA was performed by using an electroporation system (Gene Pulser, Bio-Rad, Hercules, CA, USA). The DC pulse voltage $(1.6 \mathrm{kV} / \mathrm{cm}, 1.0 \mathrm{~ms})$ was applied to the endospore standard solution. The details of this method were reported previously [28].

\subsection{Synthesis of Functional Silver Nanoparticles}

$\mathrm{Fe}_{3} \mathrm{O}_{4}$ nanoparticles were prepared in a previous report [29]. To improve the dispersibility, the PEI was prepared using a molecular weight of $25,000 \mathrm{~g} / \mathrm{mol}$. MilliQ water $(80 \mathrm{~mL})$ and $\mathrm{FeSO}_{4}(0.7 \mathrm{~g})$ were added and mixed in a Nass flask. To this solution, $\mathrm{KNO}_{3}$ $(10 \mathrm{~mL}, 2.0 \mathrm{M}), \mathrm{NaOH}(10 \mathrm{~mL}, 1.0 \mathrm{M})$, and PEI $(0.4 \mathrm{~g}, 4 \mathrm{~g} / \mathrm{L})$ were added dropwise, and 
the mixture was heated and stirred at $90{ }^{\circ} \mathrm{C}$ for $2 \mathrm{~h}$. Then, the solution was cooled at room temperature, and the $\mathrm{Fe}_{3} \mathrm{O}_{4}$ nanoparticles were trapped using a neodymium magnet and magnetically separated from the reaction mixture. The collected $\mathrm{Fe}_{3} \mathrm{O}_{4}$ nanoparticles were washed five times with MilliQ water and suspended in MilliQ water $(80 \mathrm{~mL})$ to obtain PEI-dispersed $\mathrm{Fe}_{3} \mathrm{O}_{4}$ nanoparticles (3.2 g/L, pH 7).

Silver nanoparticles were prepared as previously reported [30]. MilliQ water (97 $\mathrm{mL})$ and $\mathrm{AgNO}_{3}$ solution $(1 \mathrm{~mL}, 100 \mathrm{mM})$ were added to a beaker and heated until the solution started to boil. As soon as it started boiling, trisodium citrate solution ( $2 \mathrm{~mL}, 500 \mathrm{mM})$ was dropped into the $\mathrm{AgNO}_{3}$ solution. The heating was continued for another $15 \mathrm{~min}$ and then the solution was cooled at room temperature to obtain citric-acid-dispersed silver nanoparticles solution (Figure S1).

$\mathrm{Fe}_{3} \mathrm{O}_{4} / \mathrm{Ag}$ core-shell nanoparticles were prepared by the seeded particle growth method based on previous reports [29]. A suspension of $\mathrm{Fe}_{3} \mathrm{O}_{4}$ nanoparticles $(2 \mathrm{~mL})$ was added to a round-bottom flask and sonicated for $2 \mathrm{~min}$ in a tabletop ultrasonic cleaner $(42 \mathrm{kHz})$. Then, the prepared silver nanoparticle solution $(90 \mathrm{~mL})$ was added and stirred for $2 \mathrm{~h}$. $\mathrm{Fe}_{3} \mathrm{O}_{4}-\mathrm{Ag}$ seeds were magnetically separated from the excess silver nanoparticles solution, washed with MilliQ water five times, and suspended in MilliQ water (20 mL). PEI $(0.04 \mathrm{~g}, 2 \mathrm{~g} / \mathrm{L})$ was added and heated in an oven at $60{ }^{\circ} \mathrm{C}$ for $1 \mathrm{~h}$. After washing with MilliQ water 5 times, MilliQ water $(20 \mathrm{~mL})$ was added and $\mathrm{Fe}_{3} \mathrm{O}_{4}-\mathrm{Ag}$ seed-PEI was dispersed by sonication. Then, $\mathrm{Ag}$ shells were grown by iterative reduction of $\mathrm{AgNO}_{3}$ on $\mathrm{Fe}_{3} \mathrm{O}_{4}-\mathrm{Ag}$ seed-PEI by the following method. $\mathrm{NaOH}(110 \mathrm{~mL}, 0.01 \mathrm{M})$ was added to the $\mathrm{Fe}_{3} \mathrm{O}_{4}-\mathrm{Ag}$ seed-PEI dispersion solution and stirred. $\mathrm{AgNO}_{3}(0.5 \mathrm{~mL}, 1 \%)$ and $\mathrm{HONH}_{3} \mathrm{Cl}$ $(0.75 \mathrm{~mL}, 0.2 \mathrm{M})$ were added dropwise and reacted for $5 \mathrm{~min}$, followed by $\mathrm{AgNO}_{3}(0.5 \mathrm{~mL}$, $1 \%)$ and $\mathrm{HONH}_{3} \mathrm{Cl}(0.25 \mathrm{~mL}, 0.2 \mathrm{M})$ added dropwise for $5 \mathrm{~min}$. This 10 -min reaction was repeated five times in total. After that, the reaction mixture was magnetically separated and washed five times with MilliQ water. MilliQ water $(20 \mathrm{~mL})$ was added and dispersed by sonication to obtain $\mathrm{Fe}_{3} \mathrm{O}_{4} / \mathrm{Ag}$ core-shell nanoparticles. To dissolve the unreacted $\mathrm{Fe}_{3} \mathrm{O}_{4}$ nanoparticles, oxalic acid solution $(20 \mathrm{~mL}, 0.6 \mathrm{M})$ was prepared by mixing oxalic acid $(0.756 \mathrm{~g})$ and ammonium oxalate $(0.979 \mathrm{~g})$ in MilliQ water $(20 \mathrm{~mL})$. The prepared oxalic acid solution $(20 \mathrm{~mL})$ was added to the $\mathrm{Fe}_{3} \mathrm{O}_{4} / \mathrm{Ag}$ core-shell nanoparticle solution and stirred for $2 \mathrm{~h}$. The $\mathrm{Fe}_{3} \mathrm{O}_{4} / \mathrm{Ag}$ core-shell nanoparticles were magnetically separated from the reaction solution, washed with MilliQ water five times, and MilliQ water $(2 \mathrm{~mL})$ was added. The preparation of $\mathrm{Fe}_{3} \mathrm{O}_{4} / \mathrm{Ag}$ core-shell nanoparticles was carried out under non-magnetic conditions by using a stirrer.

Functional silver nanoparticles were prepared by modifying the surface layer of magnetic silver nanoparticles with citric acid and terbium. The prepared $\mathrm{Fe}_{3} \mathrm{O}_{4} / \mathrm{Ag}$ coreshell nanoparticles $(10 \mathrm{mg})$ were added to $0.1 \mathrm{M}$ citrate buffer solution $(1 \mathrm{~mL}, \mathrm{pH} 7)$ and allowed to react for $2 \mathrm{~h}$ in a tube rotator. Then, they were magnetically separated from the excess citrate buffer solution and washed with MilliQ water five times. $\mathrm{TbCl}_{3}(1 \mathrm{~mL}$, $0.1 \mathrm{mM}$ ) was then added and allowed to react for $2 \mathrm{~h}$. The excess $\mathrm{TbCl}_{3}$ was removed by magnetic separation, the obtained sample was washed with MilliQ water five times, and MilliQ water $(1 \mathrm{~mL})$ was added to obtain functionalized silver nanoparticles.

\subsection{Characterization of Nanoparticles}

Absorption spectra of nanoparticles were taken by UV-VIS spectrophotometer (V550DS, JASCO). Fluorescent measurements were performed using a multi-microplate reader (ARVO sx, Perkin Elmer, Waltham, MA, USA). Samples for fluorescence evaluation were prepared by adding $20 \mu \mathrm{L}$ of DPA sample to $180 \mu \mathrm{L}$ of $10 \mathrm{mg} / \mathrm{mL}$ functionalized silver nanoparticle sample. The sample $(200 \mu \mathrm{L})$ was added to a black 96-well immunoplate (Thermo Fisher Scientific, Waltham, MA, USA), and the fluorescence was measured at an excitation wavelength of $280 \mathrm{~nm}$ and a fluorescence wavelength of $545 \mathrm{~nm}$. The nanoparticles' size was measured and estimated using dynamic light scattering (DLS) measurements (DelsaMax PRO, Beckman Coulter, Brea, CA, USA). 
The morphology of synthesized nanoparticles was characterized with a transmission electron microscope (TEM) (JEM-3010, JEOL, Tokyo, Japan). Then, $10 \mu \mathrm{L}$ of the sample was prepared to be dropped on (GPS-C10 STEM Cu100P, Okenshoji Co., Ltd., Tokyo, Japan), and dried in a vacuum desiccator for $24 \mathrm{~h}$. The sample was observed by TEM at an acceleration voltage of $200 \mathrm{kV}$.

The nanoparticle dispersion solution was magnetically separated from the solvent with a neodymium magnet and vacuum dried for 1 day with a desiccator. SEM (scanning electron microscope) and EDX (energy-dispersive X-ray spectrometry) images of the $\mathrm{Fe}_{3} \mathrm{O}_{4} / \mathrm{Ag}$ core-shell nanoparticles were observed by ultra-high resolution field emission scanning electron microscope (FE-SEM) (SU9000, HITACHI, Tokyo, Japan) at $20 \mathrm{kV}$ accelerating voltage. The structural properties of the dried nanoparticle were analyzed by X-ray diffraction (XRD) (RINT-2000, Regaku, Tokyo, Japan).

Qualitative detection of DPA by Raman measurement was performed using a highspeed laser Raman microscope (RAMANtouch VIS-NIR-KUF, Nanophoton, Osaka, Japan). Functional silver nanoparticles $(180 \mu \mathrm{L})$ were added to DPA $(20 \mu \mathrm{L})$ to prepare a sample. A sample on a glass plate was added dropwise and vacuum dried with a desiccator. The dried sample was analyzed by Raman spectroscopy with an excitation laser wavelength of $533 \mathrm{~nm}$, an exposure time of $10 \mathrm{~s}$, and an integration frequency of 5 times, and a laser power of $5 \mathrm{~mW}$.

\section{Results and Discussion}

\subsection{The Sensing System in This Study}

The flow of endospore detection developed in this study is shown in Figure 1. DPA is rapidly extracted from the spores by the electroporation method, and a complex of the extracted DPA and functional silver nanoparticles is formed. After separation by a magnet, DPA is quantified by fluorescence measurement, and its qualitative nature is measured by Raman spectroscopy.

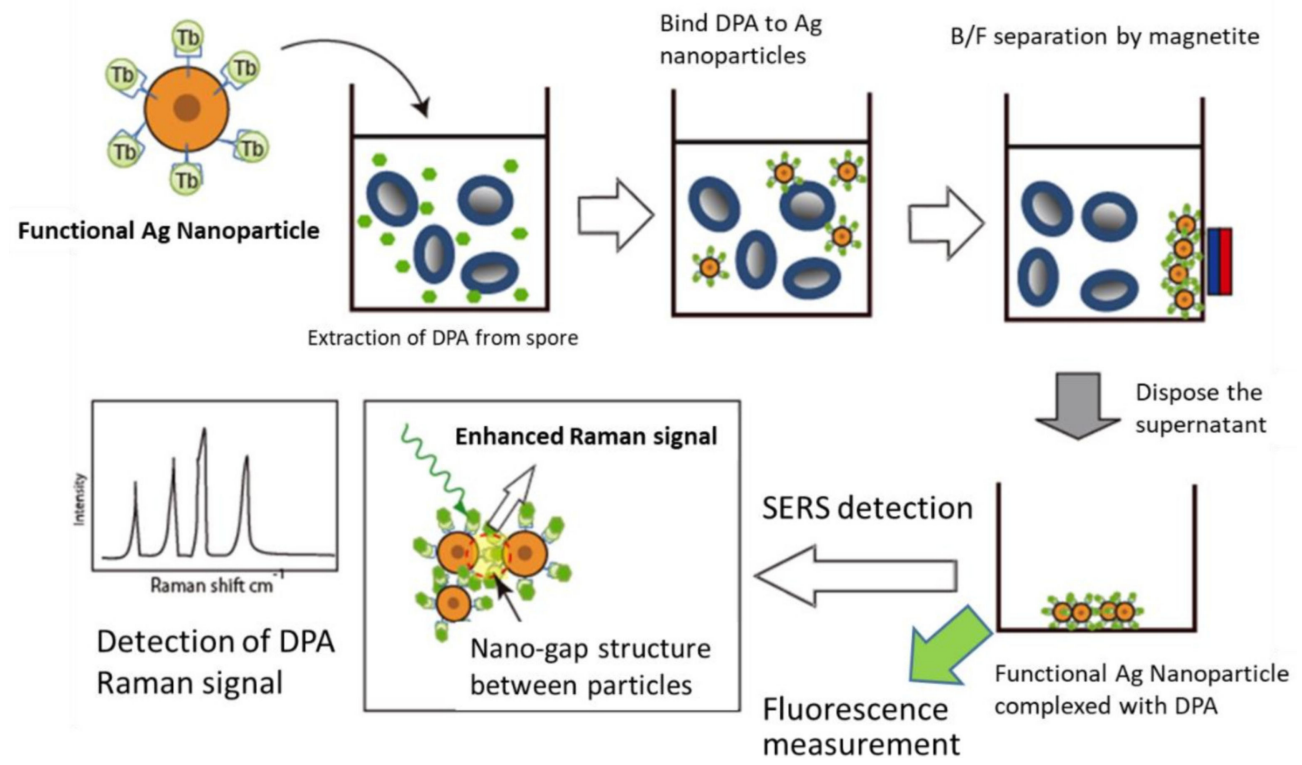

Figure 1. Schematic diagram of endospore detection system using functional silver nanoparticles.

\subsection{Preparation and Characterization of Functionalized Nanoparticles}

There have been reports on the SERS effect by silver nanoparticles [31,32], and it has been reported that SERS occurring between particles of 50-100 nm in size is most effective. Based on this information, we designed the size of functional silver nanoparticles and synthesized them. TEM images of the prepared $\mathrm{Fe}_{3} \mathrm{O}_{4}$ nanoparticles are shown in Figure 2A. From TEM observation, it was confirmed that the particles were cubic, with 
a diameter of $45 \pm 5 \mathrm{~nm}$. XRD analysis confirmed the diffraction peaks originating from $\mathrm{Fe}_{3} \mathrm{O}_{4}$ (Figure 2C). The prepared $\mathrm{Fe}_{3} \mathrm{O}_{4}$ nanoparticles could be completely separated from the solution by applying a magnetic field (Figure 2B).

(A) $\mathrm{Fe}_{3} \mathrm{O}_{4} \mathrm{NPS}$

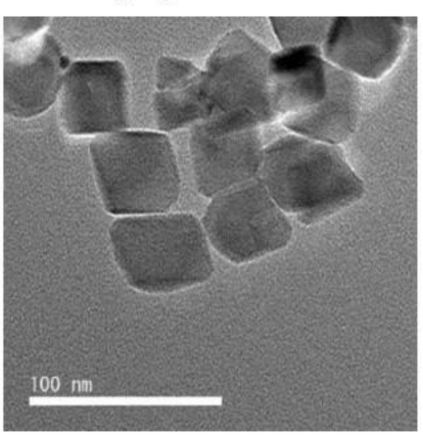

(B)

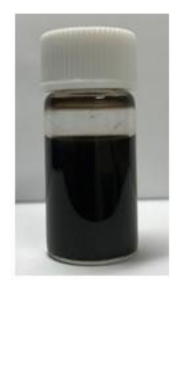

(C)

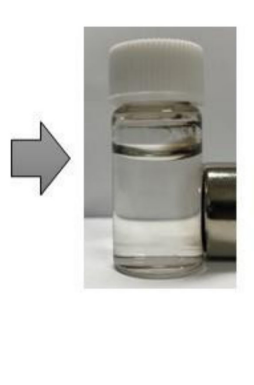

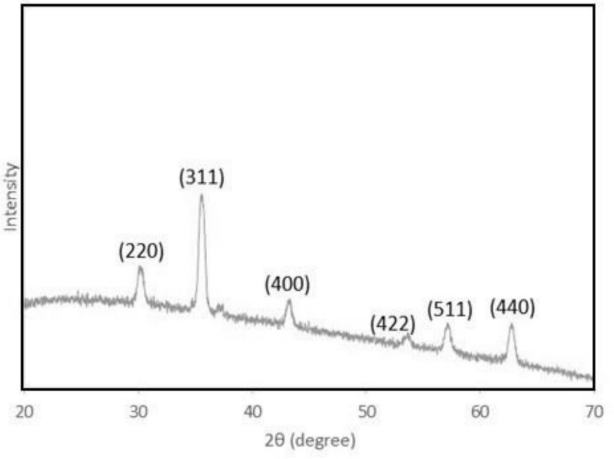

Shape : Cubic

Particle size : $45 \pm 5 \mathrm{~nm}$

Figure 2. Characterization of $\mathrm{Fe}_{3} \mathrm{O}_{4}$ nanoparticles. (A) TEM image, (B) image of separation by magnet, and (C) XRD analysis of $\mathrm{Fe}_{3} \mathrm{O}_{4}$ nanoparticles.

TEM images of the prepared $\mathrm{Fe}_{3} \mathrm{O}_{4} / \mathrm{Ag}$ core-shell nanoparticles are shown in Figure 3A. From the TEM observation, it was confirmed that the cubic $\mathrm{Fe}_{3} \mathrm{O}_{4}$ nanoparticles disappeared and spherical nanoparticles of $80 \pm 10 \mathrm{~nm}$ in diameter were constructed. Compared with the TEM image of $\mathrm{Fe}_{3} \mathrm{O}_{4}$ nanoparticles (Figure 2A), the shape of the $\mathrm{Fe}_{3} \mathrm{O}_{4}$ nanoparticles changed from cubic to spherical due to the silver coating, and the thickness of the silver shell was about $17.5 \mathrm{~nm}$. In the separation test using a magnet, the constructed nanoparticles, as well as $\mathrm{Fe}_{3} \mathrm{O}_{4}$ nanoparticles, could be completely separated from the solution by applying a magnetic field, indicating that they encapsulate $\mathrm{Fe}_{3} \mathrm{O}_{4}$ nanoparticles (Figure 3B). The results of XRD analysis are shown in Figure 3C, where the diffraction peaks derived from Ag were confirmed by XRD. The results of EDX analysis are shown in Figure 3D. From the results of elemental mapping images and EDX spectra, the Fe elements in the core and Ag elements in the shell were confirmed. From these results, we considered that the $\mathrm{Fe}_{3} \mathrm{O}_{4} / \mathrm{Ag}$ core-shell nanoparticles were prepared for the biosensing of the endospore.

\subsection{Molecular Modification and Fluorescence Detection Characterization}

The terbium complexes and DPA coordination modified on the particle surface of $\mathrm{Fe}_{3} \mathrm{O}_{4} / \mathrm{Ag}$ core-shell nanoparticles were confirmed by fluorescence measurements. In Table 1, while no significant increase in fluorescence intensity was observed at DPA concentrations $(1 \sim 5 \mathrm{nM})$, an increase in fluorescence of the functional silver nanoparticle-DPA complex was observed at each DPA concentration (10 1000 nM).

Table 1. Fluorescence intensity of the functional silver nanoparticle-DPA complex.

\begin{tabular}{cc}
\hline DPA Concentration (nM) & Fluorescence Intensity (a.u.) \\
\hline 0 & 604 \\
1 & 603 \\
5 & 608 \\
10 & 662 \\
50 & 974 \\
100 & 1194 \\
500 & 2433 \\
1000 & 4518 \\
\hline
\end{tabular}

The data represent the mean of five samples each, and a two-sample $t$-test assuming equal variance indicates a statistically significant difference at concentrations above $10 \mathrm{nM}$ at the $5 \%$ significance level. 
(A) $\mathrm{Fe}_{3} \mathrm{O}_{4} / \mathrm{Ag}$ core-shell NPs
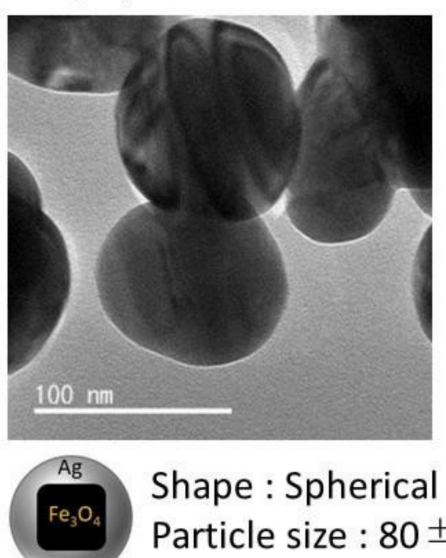

(B)

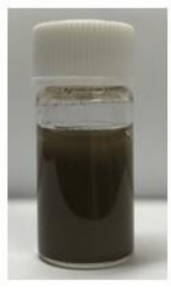

Shape : Spherical

Particle size : $80 \pm 10 \mathrm{~nm}$
(C)
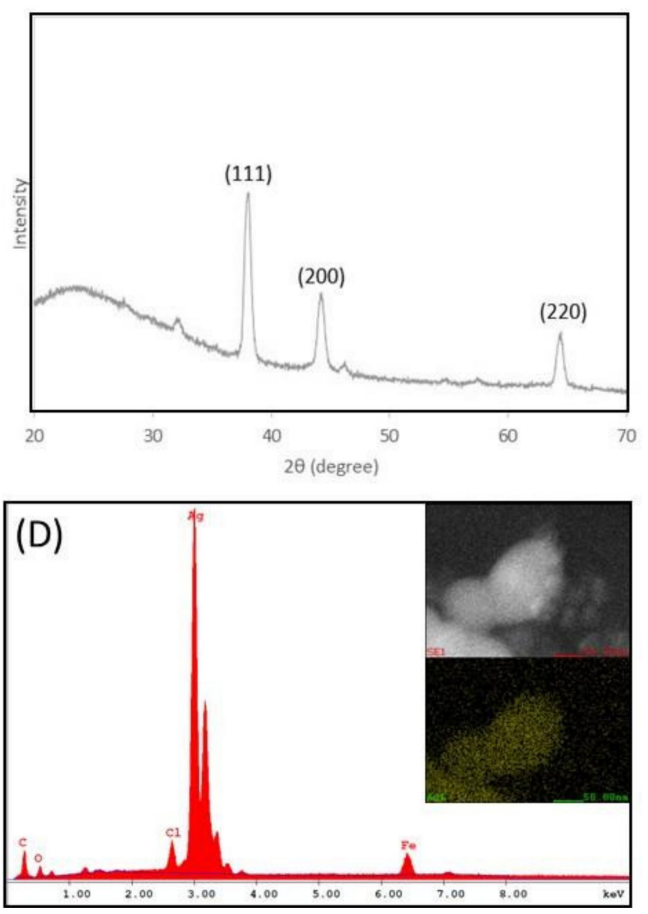

Figure 3. Characterization of $\mathrm{Fe}_{3} \mathrm{O}_{4} / \mathrm{Ag}$ core-shell nanoparticles. (A) TEM image, (B) image of separation by magnet, (C) XRD analysis of core-shell nanoparticles, and (D) SEM-EDX analysis of core-shell nanoparticles. The above image is the SEM image and the following yellow is the Ag mapping image.

The change in the fluorescence intensity of the functional silver nanoparticle-DPA complex for each DPA concentration $(10 \sim 1000 \mathrm{nM})$ prepared in the DPA standard solution is shown in Figure 4. The correlation coefficient of the DPA standard curve is 0.9949, indicating a very good linear relationship between the fluorescence intensity and the DPA concentration. In this standard curve, the detection limit (lower limit) of DPA with functionalized silver nanoparticles is $10 \mathrm{nM}$.

This excellent fluorescence property is attributed to the complexation of Tb and DPA of the functional silver nanoparticles, which results in a charge-transfer transition from the ligand DPA to the central metal $\mathrm{Tb}$, resulting in increased fluorescence emission. The $\mathrm{Tb}-\mathrm{DPA}$ complex is excited from the ground singlet state (S0) to the excited singlet state, which is then relaxed to the lowest excited singlet state (S1) by non-radiative transitions. The energy of the excited singlet state (S1) of DPA is then transferred to the excited triplet state (T1) via inter-term crossing (ISC). Subsequently, a charge transfer transition (CT) occurs from the excited triplet state (T1) of DPA to $\mathrm{Tb}$ (5D4), which emits a very strong fluorescence. In particular, the energy levels of Tb are better matched to those of DPA than those of other $\mathrm{Ln}(\mathrm{Dy}, \mathrm{Gd}, \mathrm{Eu}, \mathrm{Sm})$, and the energy transfer occurs more efficiently [33]. $\mathrm{Tb}$ has fluorescence maxima at $490 \mathrm{~nm}, 544 \mathrm{~nm}, 590 \mathrm{~nm}$, and $625 \mathrm{~nm}$ and belongs to the $5 \mathrm{D} 4 \rightarrow 7 \mathrm{~F} 6,5 \mathrm{D} 4 \rightarrow 7 \mathrm{~F} 5,5 \mathrm{D} 4 \rightarrow 7 \mathrm{~F} 4$, and 5D4 $\rightarrow$ 7F3 transitions, respectively (Figure S2). The fluorescence emission at $544 \mathrm{~nm}$ is the strongest and is used as the fluorescence measurement wavelength. The enhancement of the fluorescence intensity due to this charge-transfer transition suggests that the modification of citric acid and $\mathrm{Tb}$ on the particle surface allows the sensitive fluorescence detection of DPA. 


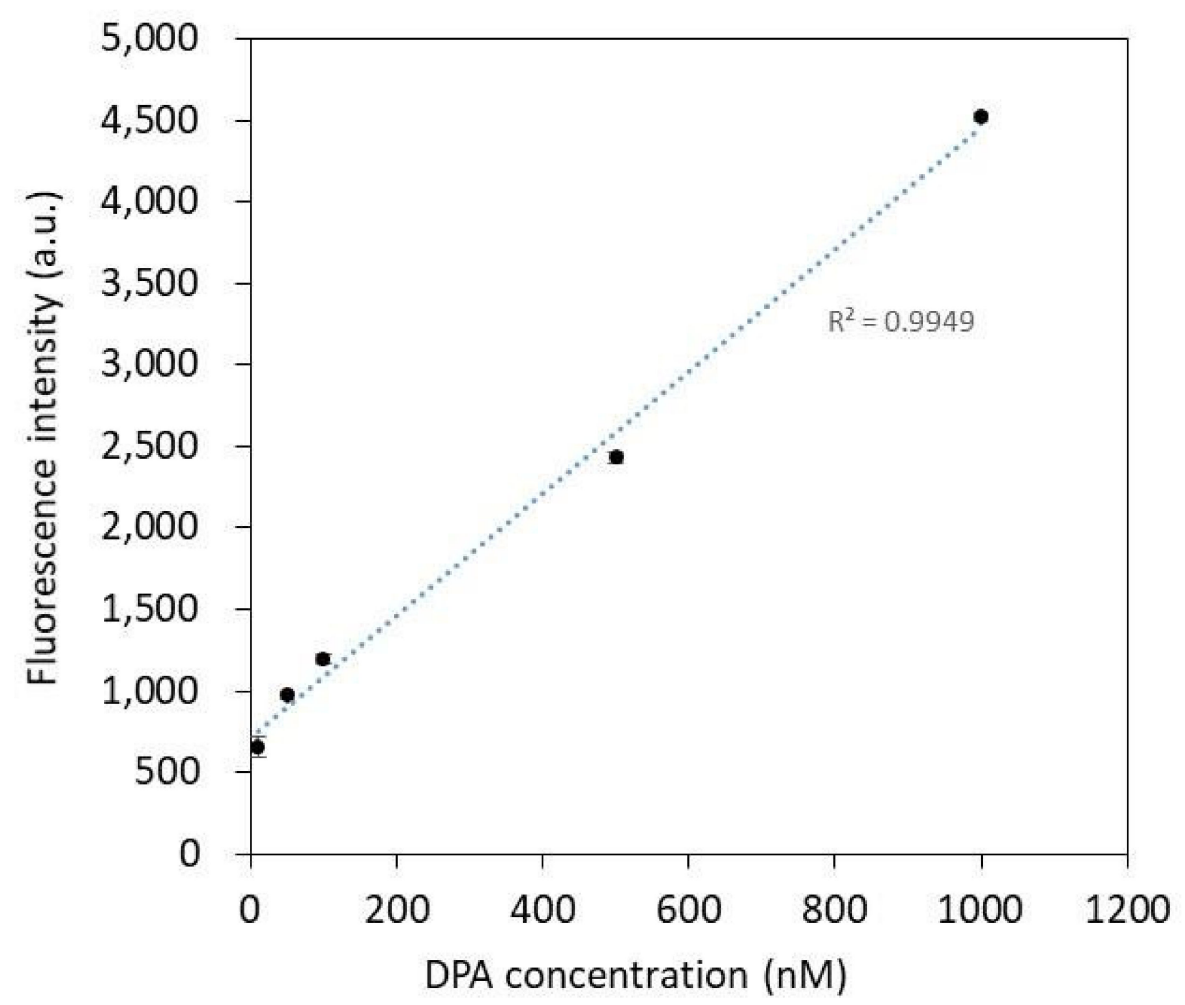

Figure 4. Calibration curve for DPA concentrations from 0 to $1 \mu \mathrm{M}$ monitored at $545 \mathrm{~nm}$ in a microplate fluorometer. The correlation coefficient of the DPA standard curve is 0.9949 . Error bars represent means $\pm \mathrm{SD}(n=5)$.

Using spore samples, the increase in fluorescence intensity of DPA extracts from spores by electroporation and a mixture of DPA extracts and functional silver nanoparticles germinated by reaction with L-Alanine for $120 \mathrm{~min}$ are shown in Figure 5. The DPA content in each sample was calculated from the increase in fluorescence intensity using the DPA standard curve determined above. The DPA concentration in the extracts treated by electroporation was about $80 \mathrm{nM}$, and that in the extracts treated with L-Alanie for $120 \mathrm{~min}$ was about $500 \mathrm{nM}$. This is close to the concentration of DPA quantified by liquid chromatography in a previous paper [28], suggesting that quantitative detection by fluorescence measurement is possible.

\subsection{Qualitative Analysis of DPA by Functionalized Silver Nanoparticles and Raman Spectroscopy}

First of all, the Raman measurement of DPA powder was carried out. The Raman spectrum of the DPA powder is shown in Figure S1. DPA consists of a pyridine ring with two carboxyl groups. The measured Raman shift of $400 \sim 1800 \mathrm{~cm}^{-1}$ contains many characteristic peaks that are useful for the identification of DPA. The Raman spectral bands of DPA powder and their attributions are shown in Figure S3 and Table S1 [34]. The pyridine ring has a characteristic peak of a very strong symmetric ring "breathing" around $1000 \mathrm{~cm}^{-1}$. Other ring vibration modes include a C-C ring bend near $640 \mathrm{~cm}^{-1}$, trigonal ring "breathing" near $1080 \mathrm{~cm}^{-1}, \mathrm{C}-\mathrm{C}$ ring mode near $1260 \mathrm{~cm}^{-1}, \mathrm{C}-\mathrm{C}$ ring stretch near $1440 \mathrm{~cm}^{-1}$, and ring stretch near $1570 \mathrm{~cm}^{-1}$. C-H bends exist around $1150 \mathrm{~cm}^{-1}$, $1170 \mathrm{~cm}^{-1}$ and $1270 \mathrm{~cm}^{-1}$. C-H out-of-plane is present around $795 \mathrm{~cm}^{-1}$ and $885 \mathrm{~cm}^{-1}$, $\mathrm{C}-\mathrm{CO}_{2}$ bend is present around $845 \mathrm{~cm}^{-1}$, and C-O stretch is present around $1315 \mathrm{~cm}^{-1}$. The carboxyl groups include $\mathrm{OCO}$ in-plane deformation at around $750 \mathrm{~cm}^{-1}$ and $\mathrm{C}=\mathrm{O}$ stretch at $1640 \mathrm{~cm}^{-1}$. 


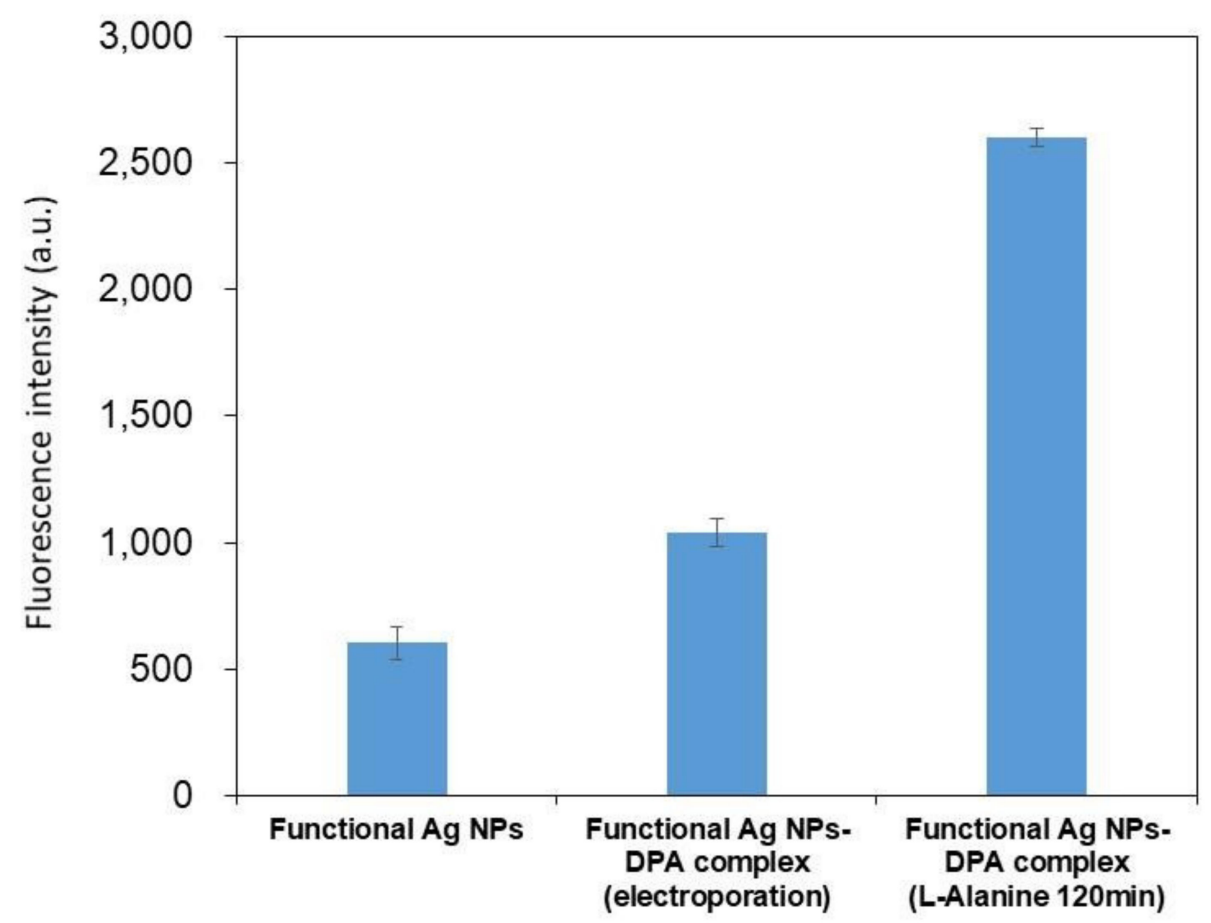

Figure 5. Increase in fluorescence intensity of DPA extract samples from spores by electroporation method, and germinated samples by reaction with L-alanine for $120 \mathrm{~min}$ mixed with functional silver nanoparticles. Error bars represent means $\pm \mathrm{SD}(n=5)$.

The qualitative evaluation of the functionalized silver nanoparticle-DPA complex was carried out based on the peak information of the Raman spectral bands. The Raman spectra of trisodium citrate dihydrate and terbium (III) chloride hexahydrate used as functional molecules are shown in Figure 6A,B, respectively. Figure 6A shows several peaks originating from the citric acid structure. The peak from terbium chloride was observed around $1600 \mathrm{~cm}^{-1}$ (Figure 6B). The Raman spectra of the constructed functionalized silver nanoparticles are shown in Figure 6C. In the Raman spectra of the functionalized silver nanoparticles, no peaks derived from functional molecules were observed. The SERS effect is caused by the resonance effect due to the electron transfer interaction between the metal surface and the adsorbed molecules, and is more likely to occur with unsaturated hydrocarbons such as aromatic compounds. Since citric acid is a saturated hydrocarbon, the signal enhancement by SERS is weak, which is considered to be the reason why the peak could not be confirmed. The Raman spectra of the functionalized silver nanoparticlesDPA complexes complexed with DPA standard solution $(1 \mu \mathrm{M})$ are shown in Figure $6 \mathrm{D}$. The complexation of functionalized silver nanoparticles with DPA confirms the SERS effect: symmetric ring "breathing" around $1000 \mathrm{~cm}^{-1}, \mathrm{C}-\mathrm{O}$ stretch around $1350 \mathrm{~cm}^{-1}$, and C-O stretch around $1440 \mathrm{~cm}^{-1}$. Symmetric ring "breathing" around $1000 \mathrm{~cm}^{-1}, \mathrm{C}-\mathrm{O}$ stretch around $1350 \mathrm{~cm}^{-1}$, and C-C ring stretch around $1440 \mathrm{~cm}^{-1}$ were identified as DPAderived peaks. In metallic nanoparticles such as gold, silver, and copper, SERS occurs, in which Raman scattered light from materials adsorbed on the surface is enhanced [31,32,35]. This phenomenon is thought to be due to the effect of the enhanced electric field of the localized surface plasmon resonance [35]. When light hits the nanoparticles, they are covered by a strong electric field due to the localized surface plasmon resonance. A very strong enhanced electric field is generated at the contact point of the particles covered by the strong electric field. Molecules at that contact point experience significant SERS effects. The enhanced electric field is surface selective because it decays exponentially with distance from the surface. The other reason it is thought to occur is resonance effects due to electron transfer interactions between the metal surface and the adsorbed molecules. In this case, the molecule must resonate against the transfer of electrons from the metal to the 
adsorbed molecule or from the adsorbed molecule to the metal. In particular, unsaturated hydrocarbons have a greater resonance effect than saturated hydrocarbons [36]. The reason for the SERS effect compared with Figure $6 \mathrm{C}$ was considered to be the resonance effect caused by the electron transfer interaction between the unsaturated hydrocarbon DPA and the metal, and the signal enhancement caused by the very strong electric field generated by the aggregation of nanoparticles.
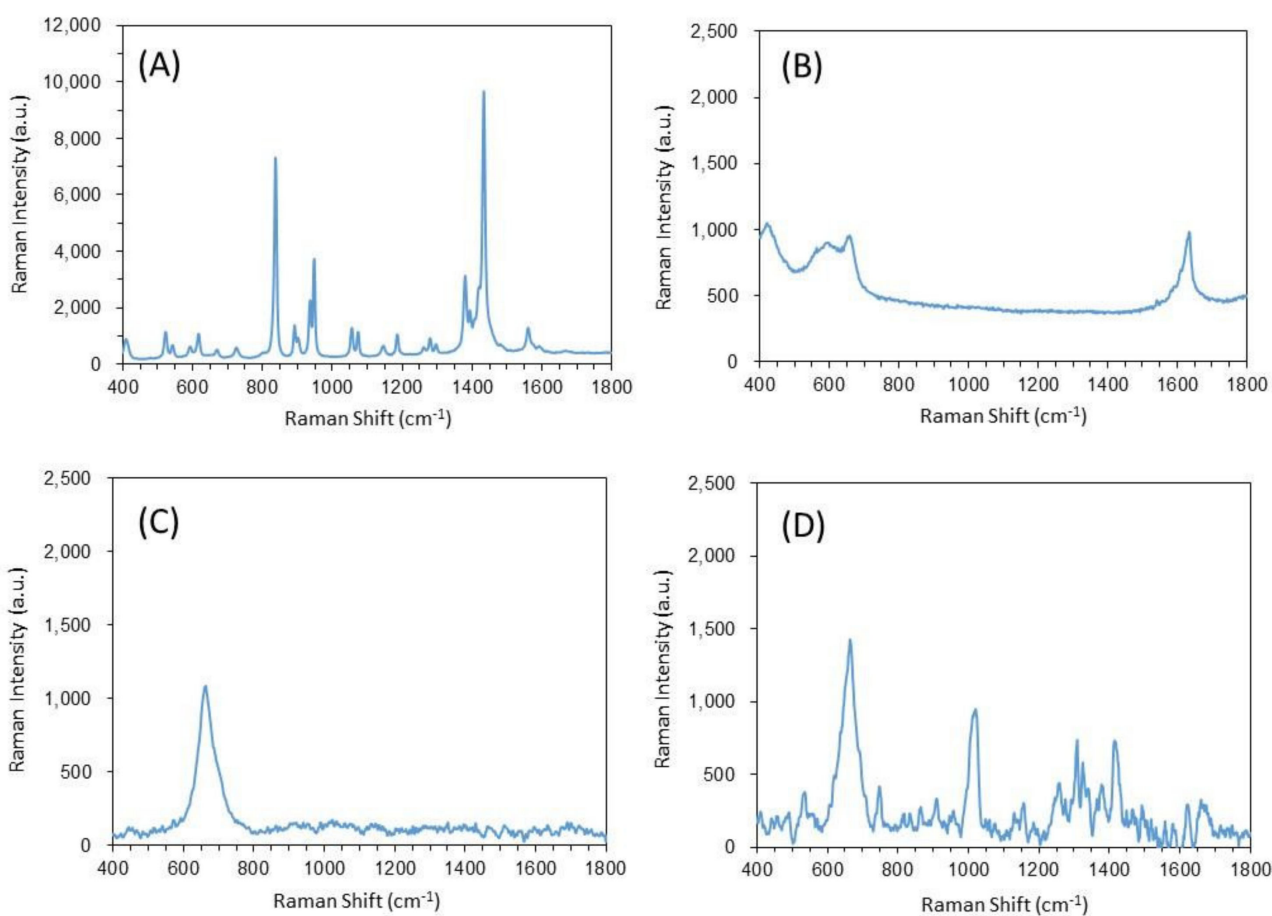

Figure 6. The qualitative evaluation by Raman spectra. (A) Trisodium citrate dihydrate, (B) terbium (III) chloride hexahydrate, (C) functionalized silver nanoparticle, and (D) functionalized silver nanoparticle-DPA complex.

The Raman spectra of the functional nanoparticles reacted with the solution extracted from the endospores by the electroporation method are shown in Figure 7. For the extracted solution, no Raman spectral peaks were observed (Figure 7a). On the other hand, the Raman spectra of the extract solution (10-fold dilution and no dilution) and the complexed functional silver nanoparticles are shown in Figure $7 c, d$, respectively. The comparison of these spectra clearly shows the enhancement of the Raman spectra, which confirms the SERS effect of functionalized silver nanoparticles. From the enhanced spectra, the symmetric ring "breathing" around $1001 \mathrm{~cm}^{-1}, \mathrm{C}-\mathrm{C}$ ring mode around $1260 \mathrm{~cm}^{-1}, \mathrm{C}-\mathrm{O}$ stretch at $1337 \mathrm{~cm}^{-1}$, and ring stretch at $1574 \mathrm{~cm}^{-1}$ can be seen. The combination of functionalized silver nanoparticles made it possible to identify multiple DPA-derived peaks in the extract from the spores, indicating the possibility of the qualitative analysis of DPA from complex Raman signals. However, the samples of diluted extract and functionalized silver nanoparticles did not show any increase in peaks that could be used for the qualitative evaluation of DPA. The SERS effect is greatly influenced by the adsorption (binding) state on the metal surface, the shape of the surface, and the aggregation state. Therefore, to further improve the sensitivity of the qualitative analysis by SERS, it is necessary to optimize the size and shape of the particles, the functional molecules that adsorb DPA, and the aggregation state of the particles after the reaction. 


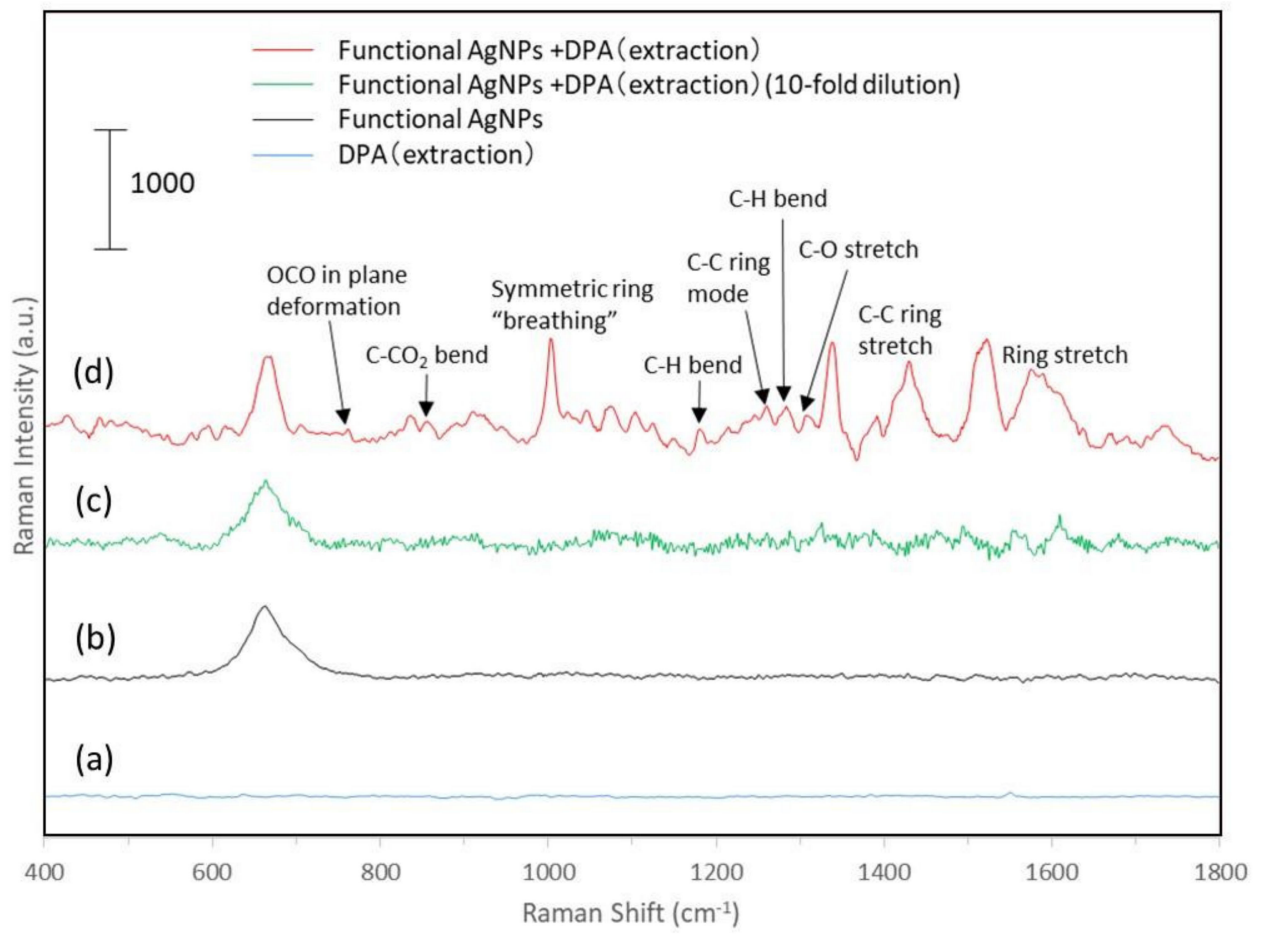

Figure 7. Raman spectra of the reaction of solution extracted from spores by electroporation method with functional Ag nanoparticles. (a) DPA extraction sample, (b) functional Ag nanoparticles, (c) 10fold dilution of DPA extraction sample with functional Ag nanoparticles, and (d) DPA extraction sample with functional Ag nanoparticles.

\section{Conclusions}

The sensor developed in this study is a simple, rapid, and accurate detection technology for such bacterial spores, and we believe that it is an essential technology for the realization of a safe and secure society, including food and pharmaceutical manufacturing sites. In addition, anthrax, which has been a hot topic for a while, forms similar spores, so this technology can also contribute to countermeasures against bioterrorism. In general, it takes three days to detect endospores from a food sample [37], and several hours even for a method that identifies the spore-forming bacteria by PCR [38]. Rapidity is especially important for detection that requires urgency. In this study, we succeeded in constructing functional Ag nanoparticles detectable by fluorescence and SERS methods for the highly sensitive detection of endospores with rapidity, and the concentration at which sporederived DPA could be quantitatively and qualitatively detected was several tens of nM. However, the concentration of spore-derived DPA required in the food industry is a few $\mathrm{nM}$. In addition, the extraction and reliable detection of DPA from spores in food is important. The SERS effect is greatly affected by the state of adsorption on the metal surface, the shape of the surface, and the aggregation state, which in turn affects the signal enhancement. In order to further increase the sensitivity of this technology for practical use, it is necessary to design particles and functional molecules and to develop methods to control the dispersion and aggregation of the particles. Additionally, when combined with a method that can extract DPA from spores in food, it will be a very powerful spore-detection tool.

Supplementary Materials: The following supporting information can be downloaded at: https: / / www.mdpi.com/article/10.3390/bios12020068/s1, Figure S1: Characterization of Ag nanoparticles; Figure S2: Fluorescence property of DPA-Tb complex; Figure S3: Raman spectrum of DPA; Table S1: Raman spectral bands of DPA powder and their attribution 


\begin{abstract}
Author Contributions: Conceptualization, S.I.; methodology, S.I. and T.M.; validation, N.H. and T.M.; formal analysis, S.I., T.M. and N.H.; investigation, T.M. and N.H.; data curation, T.M.; writingoriginal draft preparation, S.I. and T.M.; writing-review and editing, S.I.; visualization, S.I. and T.M.; supervision, S.I.; project administration, S.I.; funding acquisition, S.I. All authors have read and agreed to the published version of the manuscript.
\end{abstract}

Funding: A part of this work was funded by Iketani Science and Technology Foundation (grant number 0221041-A) and Asahi Glass Foundation.

Institutional Review Board Statement: Not applicable.

Informed Consent Statement: Not applicable.

Acknowledgments: A part of this work was conducted in Kyushu University, supported by Nanotechnology Platform Program (Molecule and Material Synthesis) of the Ministry of Education, Culture, Sports, Science and Technology (MEXT), Japan. We would like to thank Naotoshi Nakamura and Takehiko Fujigaya for helpful guidance in Raman spectra analysis.

Conflicts of Interest: The authors declare no conflict of interest.

\title{
References
}

1. Crawford, L.M.; Ruff, E.H. A review of the safety of cold pasteurization through irradiation. Food Control 1996, 7, 87-97. [CrossRef]

2. Aaliya, B.; Sunooj, K.V.; Navaf, M.; Akhila, P.P.; Sudheesh, C.; Mir, S.A.; Sabu, S.; Sasidharan, A.; Hlaing, M.T.; George, J. Recent trends in bacterial decontamination of food products by hurdle technology: A synergistic approach using thermal and non-thermal processing techniques. Food Res. Int. 2021, 147, 110514. [CrossRef] [PubMed]

3. Nicholson, W.L.; Munakata, N.; Horneck, G.; Melosh, H.J.; Setlow, P. Resistance of Bacillus Endospores to Extreme Terrestrial and Extraterrestrial Environments. Microbiol. Mol. Biol. Rev. 2000, 64, 548-572. [CrossRef] [PubMed]

4. Setlow, P. Spores of Bacillus subtilis: Their resistance to and killing by radiation, heat and chemicals. J. Appl. Microbiol. 2006, 101, 514-525. [CrossRef]

5. Slieman, T.A.; Nicholson, W.L. Role of dipicolinic acid in survival of Bacillus subtilis spores exposed to artificial and solar UV radiation. Appl. Environ.Microbiol. 2001, 67, 1274-1279. [CrossRef]

6. Goepfert, J.M.; Spira, W.M.; Kim, H.U. Bacillus Cereus: Food poisoning organism. A review. J. Milk Food Technol. 1972, 35, $213-227$. [CrossRef]

7. Tewari, A.; Abdullah, S. Bacillus cereus food poisoning: International and Indian perspective. J. Food Sci. Technol. 2015, 52, 2500-2511. [CrossRef]

8. Guinebretiere, M.H.; Girardin, H.; Dargaignaratz, C.; Carlin, F.; Nguyen, C. Contamination flows of Bacillus cereus and sporeforming aerobic bacteria in a cooked, pasteurised and chilled zucchini purée processing line. Int. J. Food Microbiol. 2003, 82, 223-232. [CrossRef]

9. Peck, M.W. Clostridium botulinum and the safety of minimally heated, chilled foods: An emerging issue? J. Appl. Microbiol. 2006, 101, 556-570. [CrossRef]

10. Lewis, J.C. Determination of dipicolinic acid in bacterial spores by ultraviolet spectrometry of the calcium chelate. Anal. Biochem. 1967, 19, 327-337. [CrossRef]

11. Warth, A.D. Determination of dipicolinic acid in bacterial spores by derivative spectroscopy. Anal. Biochem. 1983, 130, 502-505. [CrossRef]

12. Narula, A.; Rao, C.P. Fluorophoric Conjugate of N-Alkyl Naphthalimide in Sodium Dodecyl Sulfate As a Tunable and Sustainable Sensing System: Differential Sensing of $\mathrm{Zn}^{2+}$ and $\mathrm{Al}^{3+}$ and the Application of Its $\mathrm{Zn}^{2+}$ Complex in Detecting Dipicolinic Acid, a Component of Anthrax Bacterial Endospores. J. Phys. Chem. C 2019, 123, 21271-21280.

13. Hindle, A.A.; Hall, E.A. Dipicolinic acid (DPA) assay revisited and appraised for spore detection. Analyst 1999, 124, 1599-1604. [CrossRef] [PubMed]

14. Shafaat, H.S.; Ponce, A. Applications of a rapid endospore viability assay for monitoring UV inactivation and characterizing arctic ice cores. Appl. Environ. Microbiol. 2006, 72, 6808-6814. [CrossRef] [PubMed]

15. Navarro, A.K.; Pena, A.; Perez-Guevara, F. Endospore dipicolinic acid detection during Bacillus thuringiensis culture. Lett. Appl. Microbiol. 2008, 46, 166-170. [CrossRef]

16. Rosen, D.L.; Sharpless, C.; McGown, L.B. Bacterial spore detection and determination by use of terbium dipicolinate photoluminescence. Anal. Chem. 1997, 69, 1082-1085. [CrossRef]

17. Donmez, M.; Yilmaz, M.D.; Kilbas, B. Fluorescent detection of dipicolinic acid as a biomarker of bacterial spores using lanthanidechelated gold nanoparticles. J. Hazard. Mater. 2017, 324, 593-598. [CrossRef] [PubMed]

18. Tan, H.; Li, Q.; Ma, C.; Song, Y.; Xu, F.; Chen, S.; Wang, L. Lanthanide-functionalized silver nanoparticles for detection of an anthrax biomarker and test paper fabrication. J. Nanopart. Res. 2014, 16, 2151. [CrossRef]

19. Cable, M.L.; Kirby, J.P.; Sorasaenee, K.; Gray, H.B.; Ponce, A. Bacterial spore detection by $\left[\mathrm{Tb}^{3+}(\right.$ macrocycle $)($ dipicolinate $\left.)\right]$ luminescence. J. Am. Chem. Soc. 2007, 129, 1474-1475. [CrossRef] 
20. Cable, M.L.; Kirby, J.P.; Levine, D.J.; Manary, M.J.; Gray, H.B.; Ponce, A. Detection of bacterial spores with lanthanide-macrocycle binary complexes. J. Am. Chem. Soc. 2009, 131, 9562-9570. [CrossRef]

21. Fleischmann, M.; Hendra, P.J.; McQuillan, A.J. Raman spectra of pyridine adsorbed at a silver electrode. Chem. Phys. Lett. 1974, 26, 163-166. [CrossRef]

22. Jeanmaire, D.L.; Van Duyne, R.P. Surface Raman spectroelectrochemistry part I. heterocyclic, aromatic, and aliphatic amines adsorbed on the anodized silver electrode. J. Electroanal. Chem. 1977, 84, 1-20. [CrossRef]

23. Kneipp, K.; Wang, Y.; Kneipp, H.; Perelman, L.T.; Itzkan, I.; Dasari, R.R.; Feld, M.S. Single molecule detection using surfaceenhanced Raman scattering (SERS). Phys. Rev. Lett. 1997, 78, 1667-1670. [CrossRef]

24. Nie, S.; Emory, S.R. Probing single molecules and single nanoparticles by surface-enhanced Raman scattering. Science 1997, 275, 1102-1106. [CrossRef]

25. Cheng, H.W.; Huan, S.Y.; Wu, H.L.; Shen, G.L.; Yu, R.Q. Surface-enhanced Raman spectroscopic detection of a bacteria biomarker using gold nanoparticle immobilized substrates. Anal. Chem. 2009, 81, 9902-9912. [CrossRef]

26. Bell, S.E.J.; Mackle, J.N.; Sirimuthu, N.M.S. Quantitative surface-enhanced Raman spectroscopy of dipicolinic acid-Towards rapid anthrax endospore detection. Analyst 2005, 130, 545-549. [CrossRef]

27. Ghiamati, E.; Manoharan, R.; Nelson, W.H.; Sperry, J.F. UV Resonance Raman spectra of Bacillus spores. Appl. Spectrosc. 1992, 46, 357-364. [CrossRef]

28. Ikeno, S.; Maekawa, T. Instantaneous extraction of DPA from endospore for high-throughput endospore sensing. Nanobio Bionano 2016, 3, 12-14.

29. Goon, I.Y.; Lai, L.M.H.; Lim, M.; Munroe, P.; Gooding, J.J.; Amal, R. Fabrication and dispersion of gold-shell-protected magnetite nanoparticles: Systematic control using polyethyleneimine. Chem. Mater. 2009, 21, 673-681. [CrossRef]

30. Pillai, Z.S.; Prashant, V.K. What factors control the size and shape of silver nanoparticles in the citrate ion reduction method? J. Phys. Chem. B 2004, 108, 945-951. [CrossRef]

31. Guo, H.; Zhang, Z.; Xing, B.; Mukherjee, A.; Musante, C.; White, J.C.; He, L. Analysis of silver nanoparticles in antimicrobial products using surface-enhanced Raman spectroscopy (SERS). Environ. Sci. Technol. 2015, 49, 4317-4324. [CrossRef] [PubMed]

32. Stamplecoskie, K.G.; Scaiano, J.C.; Tiwari, V.S.; Anis, H. Optimal size of silver nanoparticles for surface-enhanced Raman spectroscopy. J. Phys. Chem. C 2011, 115, 1403-1409. [CrossRef]

33. Li, Q.; Yue, D.; Lu, W.; Zhang, X.; Li, C.; Wang, Z. Hybrid luminescence materials assembled by [Ln (DPA) $\left.{ }^{3}\right]^{3-}$ and mesoporous host through ion-pairing interactions with high quantum efficiencies and long lifetimes. Sci. Rep. 2015, 5, 8385. [CrossRef] [PubMed]

34. Kolomenskii, A.A.; Schuessler, H.A. Raman spectra of dipicolinic acid in crystalline and liquid environments. Spectrochim. Acta Part A 2005, 61, 647-651. [CrossRef]

35. Futamata, M.; Yu, Y.; Yajima, T. Elucidation of electrostatic interaction between cationic dyes and Ag nanoparticles generating enormous SERS enhancement in aqueous solution. J. Phys. Chem. C 2011, 115, 5271-5279. [CrossRef]

36. Otto, A. The 'chemical' (electronic) contribution to surface-enhanced Raman scattering. J. Raman Spectrosc. 2005, 36, 497-509. [CrossRef]

37. Vandeweyer, D.; Lievens, B.; Van Campenhout, L. Identification of bacterial endospores and targeted detection of foodborne viruses in industrially reared insects for food. Nat. Food 2020, 1, 511-516. [CrossRef]

38. Kędrak-Jabłońska, A.; Budniak, S.; Szczawińska, A.; Reksa, M.; Krupa, M.; Szulowski, K. Evaluation of real-time PCR based on SYBR Green I fluorescent dye for detection of Bacillus anthracis strains in biological samples. J. Vet. Res. 2018, 62, 549-554. [CrossRef] 